CLINICAL TOPIC REVIEW

\title{
Ketamine for paediatric sedation/analgesia in the emergency department
}

\section{C Howes}

Emerg Med J 2004;21:275-280. doi: 10.1136/emj.2003.005769

This review investigates the use of ketamine for paediatric sedation and analgesia in the emergency department

pain or other noxious stimuli, with relative preservation of respiratory and cardiovascular functions despite profound amnesia and analgesia, ${ }^{10}{ }^{30-32}$ described as "cataleptic." ${ }^{10}$ This trancelike state of sensory isolation provides a unique combination of amnesia, sedation, and analgesia. ${ }^{7} 103031$ The eyes often remain open, though nystagmus is commonly seen. Heart rate and blood pressure remain stable, and are often stimulated, possibly through sympathomimetic actions. ${ }^{30} 3133$ Functional residual capacity and tidal volume are preserved, with bronchial smooth muscle relaxation ${ }^{34-37}$ and maintenance of airway patency and respiration..$^{10} 303138$

However, despite the enthusiasm of many authors and practitioners, ketamine may not be the ideal agent. Emergence reactions, subanaesthetic conditions, and airway problems do occur, ${ }^{10} 16^{39-41}$ and it is generally recommended that only physicians skilled in airway management and resuscitation are involved in the care of sedated children.

Is ketamine sedation the answer for the unconsolable injured child requiring a painful procedure in the emergency department? Such a child could require exploration of a wound, a strange adult with instruments invading the child's personal space, and attention to functional and cosmetic outcome. Assuming distraction therapy has failed, a three part question can be formulated thus:

"In [children with injuries requiring a painful procedure] is [ketamine sedation/analgesia] a [safe and acceptable technique in the A\&E department]?"

the preference of the parent, who acts as child's advocate; lastly, the procedure proposed.

The phencyclidine derivative ketamine has been described as the ideal agent for paediatric sedation in $\mathrm{EDs}^{8-18}$ with departments in the UK, ${ }^{19-21}$ USA, $^{22}{ }^{23}$ Australia ${ }^{24}$ Europe, Japan, Mexico, the Middle East (Green SM unpublished data), and Singapore ${ }^{26}$ using the technique regularly. The American College of Emergency Physicians $^{27}$ and the Australasian College of Emergency Medicine ${ }^{28}$ both have formal guidelines for emergency physicians specifically for ketamine sedation, although the latest national guideline on paediatric sedation in the United Kingdom recommends "...the general anaesthetic agents [...ketamine...]....are only used by those formally trained in paediatric or neonatal anaesthesia or intensive care..."29

Ketamine is a unique drug giving complete anaesthesia and analgesia with preservation of vital brain stem functions. This "dissociative" state has been described as "a functional and neuro-physiological dissociation between the neocortical and limbic systems." ${ }^{\prime 30}$ Ketamine dissociation results in a clinical state of lack of response to

\section{LITERATURE SEARCH}

Databases: Medline 1966 to present and Embase 1980 to present via the Ovid interface.

To specify trials involving the randomised comparison of ketamine with other sedative agents the following strategy was used:

"ketamine.mp. AND (children or child\$ or paediatric or paediatric $\$$ or pediatric or pediatric\$). mp." AND ( maximally sensitive randomised control trial filter). ${ }^{43}$

A further search for additional papers was performed with the following strategy: (ketamine or ketamin\$).mp. AND (children or child\$ or paediatric or paediatric\$ or pediatric or pediatric\$).mp. AND (emergency or emergenc\$ or accident or accident\$ or (accident and emergency)).mp.

No limits were applied. The results were assessed for relevant articles by searching the abstracts. The references of review articles were also searched for any additional papers of 
relevance, and the following journals were hand searched for recent articles not yet included in the Medline or Embase databases that may be relevant: Annals of Emergency Medicine, Academic Emergency Medicine, Emergency Medicine Journal, Emergency Medicine, American Journal of Emergency Medicine, Pediatric Emergency Care.

Other sources include data from Lancaster Royal Infirmary and communications with authors in the field of ketamine sedation in children in A\&E (Ray McGlone, Lancaster, UK, and Steven Green, California).

\section{RESULTS}

\section{Randomised trials comparing ketamine with other agents}

When comparing agents used for sedation the primary outcome measures must be the characteristics of our mythical "ideal agent." ${ }^{67}$

Only three trials were identified that directly compared ketamine alone with another sedative agent. Others used combinations of sedatives, were studying ketamine in the context of general anaesthesia for surgery in an operating environment, or studying the pharmacology of ketamine. Others studied ketamine for critical care procedures. One study was placebo controlled. Table 1 summarises these three trials. The trial published by Acworth $e t a l^{44}$ is included to highlight UK experience and the attempts at blinding the investigators made. The trial was confounded as ketamine was given with midazolam.

It is difficult to perform a truly blinded comparison of sedative agents.

Acworth $e t$ a ${ }^{44}$ blinded the observers by bringing them into the sedation room to score the sedation level after drug administration and placing dummy intravenous cannulas on the patients. They also attempted to perform a quality control on their blinding by asking the observers to guess which sedation agent had been given; observers were right in 55\%. However, these observers may introduce bias as the ketamine dissociated state can be recognised from other sedation levels. ${ }^{10}{ }^{17} \mathrm{~A}$ study blinding the data analysis from the clinicians has yet to be reported, and so additional bias remains in the published work. Varying sedation scoring systems, and definitions of "agitation" and "satisfaction" complicate the analysis. The conclusion is that ketamine appears to provide better conditions of sedation, though a somewhat different level of sedation than other agents. Definitions of sedation levels will be dealt with later in this review.

Attempts to compare side effects of sedative agents would require statistical powering. Green $e t$ al ${ }^{45}$ calculated that 7216 subjects would be required for a study to detect a $50 \%$ relative difference in airway complications from a baseline incidence of $1.4 \%$. Differences in defining and reporting adverse events may also invalidate reporting of such incidents. Without large, prospective, multicentre, randomised trials we have to rely on large case studies; the evidence from these studies may make a future randomised comparison unethical. ${ }^{45} 46$

\section{Safety and side effect profile: observational studies and reviews}

Green and Johnson published a comprehensive review of ketamine sedation in $1990,{ }^{10}$ alongside a case series of 108 episodes of paediatric sedation in an ED. ${ }^{38}$ The authors pooled data from published reports including their own data on the use of ketamine sedation in the unintubated patient, and demonstrated an excellent safety profile in a wide range of procedures and settings, including burns ward dressing changes, cardiac catheterisation, dentistry or oral surgery, and minor surgery. Altogether 11589 cases (97 case series) of

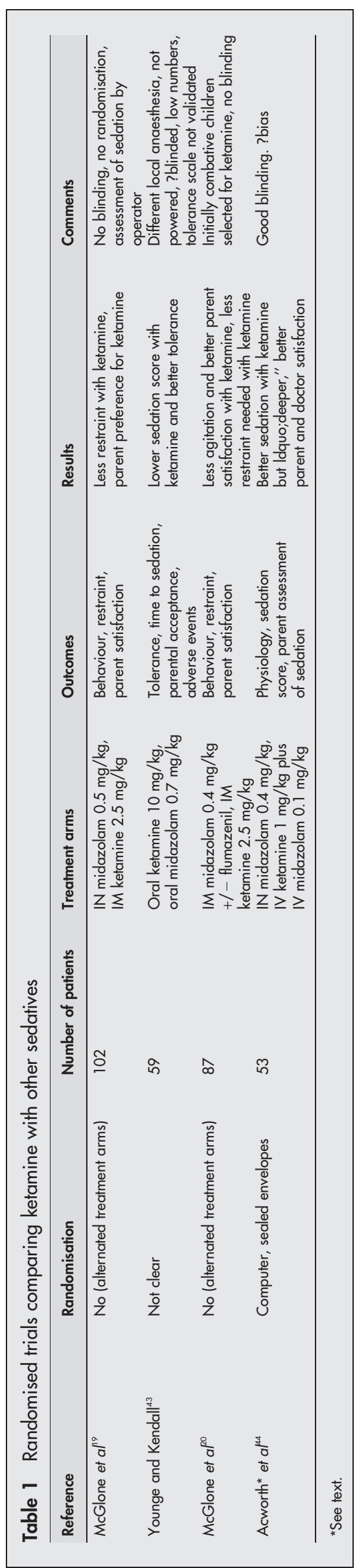


paediatric sedation using ketamine are discussed and this is by far the most comprehensive review of the topic.

The authors quoted incidences of adverse events as follows (with referenced comments).

Apnoea: "exceptionally rare"

Spontaneous respiration is maintained with ketamine dissociation, although the review ${ }^{10}$ quoted incidences of transient apnoea after rapid intravenous administration or exceptionally high doses.

Apnoea has since been reported after intramuscular administration. ${ }^{16}{ }^{41}$

Ketamine has been used successfully for many years as the sole agent to facilitate surgical and other procedures in remote third world locations without skilled anaesthetists present or supplemental oxygen, ${ }^{47-49}$ in battlefield and prehospital trauma victims, ${ }^{50-53}$ and in the ED during resuscitation of trauma victims for analgesia during manipulation and splinting of fractures (unpublished data). Green et $a l^{54}$ have reported the maintenance of spontaneous respiration in children receiving $5(n=3), 10(n=5)$, or $100(\mathrm{n}=1)$ times the intended doses of ketamine. Two cases required brief periods of assisted ventilation, and two maintained spontaneous breathing but were intubated prophylactically to protect the airway. None of the recent case series have reported any episodes of apnoea requiring intervention other than supplemental oxygen or brief manual ventilation assistance (table 2 ).

\section{Laryngospasm: very rare-intubation required in} two cases $(0.017 \%)$

The reported incidence in paediatric general anaesthesia is $0.87 \%$, with children less than 10 years old more susceptible (1.74\%) (Olssen and Hallen, 1984. Cited by Green et $a l^{10}$ as reference 158). Although Green et $a l^{10}$ highlight the safe use of ketamine sedation for dental surgery and tonsillectomy, they have subsequently reported an increased incidence (9.5\%, all occurring during oesophagogastroscopy) in procedures entailing stimulation of the oropharnx or hypopharnx. ${ }^{55}$ All of these episodes were transient with minimal clinical impact.

It is accepted that instrumentation of the hypopharynx including suctioning may precipitate an episode of laryngospasm. To help prevent the salivation associated with ketamine most authors recommend concurrent administration of an antisialogogue. Salivation may still occur if atropine is given ( 59 of 501 cases, $12 \%) .^{40}$ Green et al reported an incidence of hypersalivation of $1.7 \%{ }^{16} \mathrm{~A}$ randomised controlled trial may answer the question of whether antisialogogues prevent the salivation associated with ketamine.

\section{Emergence phenomena: 0\%-10\%-less common with IM administration. Rarely upsetting for children under 10 years old}

Emergence reactions (sensory misinterpretation-"trips", vivid hallucinations, "floating feelings", bizarre behaviour) were all reported. These are manifestations of ketamine's unique effect of sensory isolation, recovering via sensory misinterpretation. ${ }^{30}{ }^{31}$ It is felt that children find this effect less disturbing than adults because of their different perception of the world and their environment. The incidence of emergence reactions is said to increase with age, but can be reduced by positive psychology ("think of a nice dream"), and avoiding ketamine in patients prone to vivid dreaming or psychosis. ${ }^{10}$ Some authors advocate adjunctive midazolam to prevent emergence phenomena, but two randomised trials $^{5657}$ and a topic review ${ }^{58}$ have shown this to be ineffective, with oxygen desaturation occurring more frequently in the midazolam treated group. ${ }^{56}$ Green and

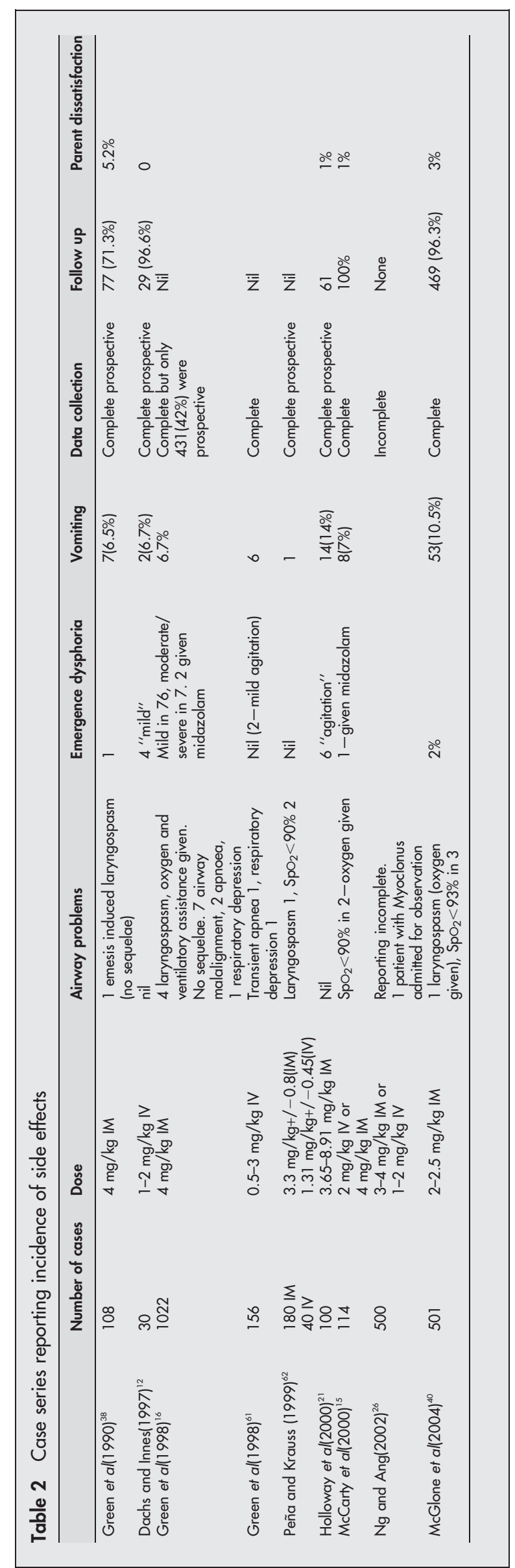


Johnson conclude "it is highly unlikely that ketamine causes permanent changes in personality or intellectual function."10

In a series of 501 cases at Lancaster ${ }^{40}$ using a lower (often subdissociative) dose of 2.0 to $2.5 \mathrm{mg} / \mathrm{kg}$ we found an incidence of emergence "euphoria" of $2 \%$. None of these children had any recollection of the sedation, or feelings of anxiety or distress afterward, and parents reported a $98 \%$ level of satisfaction.

Vomiting: $8.5 \%$ from the pooled data $(0 \%-43 \%)$, all but two cases during recovery

Postoperative vomiting from general anaesthesia in children is quoted as ranging from $0 \%$ to $70 \%{ }^{59}$ Vomiting after discharge from hospital may be influenced by early mobilisation or motion sickness during the car ride home..$^{40}$ Despite variations in fasting recommendations including instances of sedation in unfasted patients, there were no episodes of aspiration reported. Green and Krauss have since argued that fasting recommendations for ED sedation may be unnecessary in view of the lack of evidence of pulmonary aspiration risk, particularly if ketamine is used. ${ }^{60}$

Other reactions: nystagmus, ataxia, myoclonus, random limb movements, opisthotonus. Transient facial rash or flushing

Rarely clinically important and resolve with recovery. Ataxia may persist for up to four hours. It is recommended that children recovering from ketamine sedation be kept still, lying down, and quiet, until nystagmus and uncoordination have resolved..$^{10} 16$

Since this review was published, Green et al attempted to determine predictors of adverse events during intramuscular ketamine sedation, ${ }^{45}$ again using their data from 1022 cases. $^{16}$ Multiple logistic regression analyses were used to determine the association of five variables (age, sex, ASA risk, ketamine dose, number of doses) with vomiting and recovery agitation. No variable was found to be associated with airway complications. Emesis was modestly associated with age over 5, with a difference in incidence of $8.6 \%$ (95\% CI $4.9 \%$ to $12.1 \%)$. Age under 5 was associated with an increased incidence of recovery agitation (22.5\% compared with $12.1 \%$ in the over 5 year age group); the reduction in incidence of vomiting in the children over 5 was $-10.4 \%$ ( $95 \%$ CI $-3 \%$ to $-17.7 \%$ ). The incidence of recovery agitation was $17.9 \%$ in ASA class 1 children and $33.3 \%$ in ASA class 2 or more, a difference of $-15.4 \%$ (95\% CI $0 \%-30.7 \%$ ).

Further observational studies and reviews have appeared since Green's large review ${ }^{10}$ of ketamine sedation in children. These add smaller numbers to the data, but with the important emphasis on ED practice of ketamine sedation. $^{8}{ }^{12} 14-1621242640$ 60-67

Table 2 shows the reported incidence of side effects of ketamine from these eight observational studies reporting on the use of ketamine as a sedative/analgesic in the unintubated patient in an emergency department setting. One of these was retrospective and incomplete in the reporting of side effects, ${ }^{26}$ although the authors did report 18 patients admitted because of "failure of the procedure" (not failure of sedation), and one admission for observation (myoclonic jerks were observed in the context of a minor head injury). The rest, though prospective, varied in their data collection. The most common side effects were emesis, emergence dysphoria, and airway problems. None of the airway problems encountered resulted in patient harm, and all were effectively dealt with. No patient required intubation. Parent dissatisfaction, where reported, ranged from $1 \%$ to $5.2 \%$. In our recent series from Lancaster ${ }^{40} 15$ parents (3\%) expressed dissatisfaction: only four rated their dissatisfaction to sedation related issues. In Green's series, ${ }^{38}$ of the four dissatisfied parents only one had a complaint related to the sedation procedure.

\section{Doses of ketamine used}

In Green's original review of 11589 administrations ${ }^{10}$ dose ranges from 0.5 to $16 \mathrm{mg} / \mathrm{kg} \mathrm{IM}$ and 1 to $5 \mathrm{mg} / \mathrm{kg}$ IV were reported. Modern ED practitioners tend to use 2 to $5 \mathrm{mg} / \mathrm{kg}$ IM or 0.5 to $2 \mathrm{mg} / \mathrm{kg} \mathrm{IV.}{ }^{12} 151620212640$

In a further review, Green et al tried to determine the optimum dose of ketamine for paediatric sedation. ${ }^{66}$ Analysis of the previously reported database of 1022 cases $^{16}$ was performed to compare adequacy of sedation, time to discharge, and adverse events with the dose of ketamine administered. These data had been collected prospectively in $42 \%$ of cases, the rest by retrospective review of the case notes. Cases were divided up by dose increments of $0.5 \mathrm{mg} /$ $\mathrm{kg}$. No clinical or statistical difference in time to discharge, adverse events, emesis, recovery agitation, time to discharge, and adequacy of sedation was found in any dose groups, though there was a non-significant trend towards improved sedation adequacy with increasing dose. The authors concede a randomised double blind comparison of two doses would be an ideal test of their findings, but calculated that they would require 1942 subjects to detect a 3\% absolute improvement in sedation adequacy. They concluded that $4-5 \mathrm{mg} / \mathrm{kg}$ IM produced adequate sedation in $93 \%-100 \%$ of children.

Our Lancaster study reports the lowest dose used in EDs. ${ }^{40}$ A dose of 2.0 to $2.5 \mathrm{mg} / \mathrm{kg}$ IM was given to 501 patients for minor wound repairs. Data collection was complete, and the measure of sedation adequacy used was "degree of restraint" required. Although full dissociation probably did not occur in a proportion of patients (discussion among the authors), "significant" restraint (defined as restraint of arms, legs, and head) was required in less than $2 \%$ of cases; it was felt that the term "restraint" was also poorly defined and the nursing staff completing the forms admitted that "repositioning" or "gentle guiding" of limbs was coded under the "restraint" heading.

The studies from the United States using doses of 4-5 mg/ kg IM, show a tendency to perform more painful procedures in the ED such as fracture manipulations. ${ }^{10} 151638626467$ McGlone's papers ${ }^{19} 2040$ demonstrate the use of ketamine $2.0-2.5 \mathrm{mg} / \mathrm{kg}$ IM for minor procedures such as simple wound toilet and suture with local anaesthetic. It appears that the incidences of side effects may not be dose related, though McGlone et a ${ }^{40}$ did show a tendency to less incidence of airway complications with $2 \mathrm{mg} / \mathrm{kg}$ - the confidence intervals were wide, and the study was not randomised or blinded. It is doubtful if a randomised, controlled, blinded trial comparing doses will be ever be conducted in light of published data and ethical considerations.

\section{Definitions of sedation and what does "ketamine sedation" mean?}

It is generally accepted that the term "conscious sedation" refers to a state of drug induced central nervous system depression, where the verbal contact is maintained with the patient, and airway and other reflexes are preserved. ${ }^{27} 286869$ Sedation to a deeper level implies loss of verbal contact and response to gentle stimulation. This state of "deep sedation" risks the loss of protective reflexes, airway control, aspiration, and hypoxia. "Deep sedation" carries a requirement for a level of care consistent with general anaesthesia. ${ }^{67-29} 666869$ The drugs used should have a wide margin of safety so that loss of consciousness is unlikely. ${ }^{65-29} 6869$

As described above, the state of ketamine dissociation does not follow this continuum of gradually increasing depth of sedation and concurrent cardiorespiratory depression, towards a state of general anaesthesia. Any sedative drug 
used in large enough quantities, or with a susceptible patient, will produce a state of general anaesthesia. ${ }^{65} 6869$ (Midazolam, commonly used for sedation, was originally marketed and introduced as a general anaesthetic induction agent). Is the state of dissociation seen with ketamine actually general anaesthesia if no verbal, motor, or cardiovascular response to painful stimuli is observed?

It is commonly accepted that general anaesthesia, by definition, results in partial or total lack of airway reflexes, resulting in an inability to independently maintain an airway. From this topic review it seems ketamine dissociation occurs with maintenance of respiration and a patent airway in most situations probably because its primary site of action is the cerebral cortex and limbic systems and not the brain stem. ${ }^{30} 31$

There is no gradual slide from sedation to general anaesthesia with ketamine. ${ }^{17}$ No dose-response continuum is observed and patients are either dissociated or they are not, with no progressive "depth" of dissociation. ${ }^{17}$ EEG analysis of ketamine dissociated subjects fails to show the classic depression of the bispectral index seen in general anaesthesia ${ }^{17} 70$

Ketamine cannot therefore be classified by current guidelines on sedation. Green proposed a separate sedation category to describe the dissociative state demonstrated by ketamine. ${ }^{66}$ He later defined "dissociative sedation" thus:

"A trancelike cataleptic state characterised by profound analgesia and amnesia, with retention of protective airway reflexes, spontaneous respirations, and cardiopulmonary stability. ${ }^{\prime \prime 17}$

\section{CONCLUSIONS - WITH REFERENCE TO THE THREE PART QUESTION}

In children with injuries requiring a painful procedure ketamine dissociative sedation is a safe and acceptable technique in the emergency department.

Ketamine "dissociative sedation" is different from conscious sedation, deep sedation, and general anaesthesia. The rare instances of serious side effects necessitate the availability of experienced staff skilled in advanced airway maintenance, with adequate monitoring and resuscitation equipment. To provide a ketamine sedation service, EDs must be able to comply with the above; it may be that staffing levels, service commitments, and workload mean that children who could otherwise be managed in the emergency department and discharged home will have to be referred to another unit, or to an in-hospital team for general anaesthesia. This may mean an inter-hospital transfer if no paediatric anaesthetist is on site. ${ }^{71}$ Paediatric or general anaesthetists should not be required to assist emergency physicians sedating children with ketamine. ${ }^{72}$

As more EDs in the UK introduce a ketamine sedation protocol, our specialty must ensure, above all, the safety of our patients. ${ }^{965}$ Full and comprehensive prospective national audit is proposed and it is hoped that all departments around the country using ketamine for paediatric sedation will participate (personal communication).

\section{REFERENCES}

1 Kennedy RM. The "ouchless emergency department" getting closer: advances in decreasing distress during painful procedures in the emergency department. Pediatr Clin North Am 1999;46:1215-47.

2 Kleinknecht RA. Acquisition of blood, injury, and needle fears and phobias. Behav Res Ther 1994;32:817-23.

3 Trigwell PJ. latrogenic needle phobia. [Letter]. Br Dent J 1993;174:158.

4 Maurice SC, O'Donnell JJ, Beattie TF. Emergency analgesia in the paediatric population. Part II pharmacological methods of pain relief. Emerg Med J 2002;19:101-5.
5 O'Donnell JJ, Maurice SC, Beattie TF. Emergency analgesia in the paediatric population. Part III non-pharmacological measures of pain relief and anxiolysis. Emerg Med J 2002;19:195-7.

6 Doyle E. Emergency analgesia in the paediatric population. Part IV paediatric sedation in the emergency department: pros and cons. Emerg Med J 2002;19:284-7.

7 Blackburn P, Vissers R. Pharmacology of emergency department pain management and conscious dissociation. Emerg Med Clin North Am 2000;18:803-27

8 Epstein FB. Ketamine dissociative sedation in pediatric emergency medicine practice. Am J Emerg Med 1993;11:180-2.

9 Sobel RM, Morgan BW, Murhy M. Ketamine in the ED: medical politics versus patient care. Am J Emerg Med 1999;17:722-5.

10 Green SM, Johnson NE. Ketamine sedation for pediatric procedures: Part 2, review and implications. Ann Emerg Med 1990;19:1033-46.

11 Heckman JD. The use of dedamine sedation. J Bone Joint Surg [Am] 2000;82-A:911.

12 Dachs RJ, Innes GM. Intravenous ketamine sedation of pediatric patients in the emergency department. Ann Emerg Med 1997;29:146-50.

13 Ducharme J. Ketamine: Do what is right for the patient. Emerg Med 2002;13:7-8.

14 Sacchetti A. Pediatric sedation and analgesia. Emerg Med 1995;27:67-87.

15 McCarty EC, Mencio GA, Walker LA, et al. Ketamine sedation for the reduction of children's fractures in the emergency department. J Bone Joint Surg [Am] 2000;82-A:912-18.

16 Green SM, Rothrock SG, Lynch EL, et al. Intramuscular ketamine for pediatric sedation in the emergency department: safety profile in 1,022 cases. Ann Emerg Med 1998;31:688-97.

17 Green SM, Krauss B. The semantics of ketamine. Ann Emerg Med 2000;36:480-2.

18 Adams HA, Hemplemann G. Twenty years of ketamine-a retrospective view. Anaesthetist 1990;39:71-6.

19 McGlone RG, Ranasinghe S, Durham S. An alternative to "Brutacaine": a comparison of low dose intramuscular ketamine with intranasal midazolam before suturing. J Accid Emerg Med 1998;15:231-6.

20 McGlone R, Fleet T, Durham S, et al. A comparison of intramuscular ketamine with high dose intramuscular midazolam with and without intranasal flumazenil in children before suturing. Emerg Med J 2001;18:34-8.

21 Holloway VJ, Husain HM, Saetta JP, et al. Accident and emergency department led implementation of ketamine sedation in paediatric practice and parental response. J Accid Emerg Med 2000;17:25-8

22 Ilkhanipour K, Juels CR, Langdorf MI. Pediatric pain control and conscious sedation: a survey of emergency medicine residents. Acad Emerg Med 1995; 1:368-72.

23 Hostetler MA, Auinger P, Szilagyi PG. Parenteral analgesic and sedative use among ED patients in the United States: combined results from the National Hospital Ambulatory Medical Care Survey (NHAMCS) 1992-1997. Am J Emerg Med 2002;20:83-7 and erratum in Am J Emerg Med 2002;20:496.

24 Priestly SJ, Taylor J, McAdam CM, et al. Ketamine sedation for children in the emergency department. Emerg Med 2001;13:82-90.

25 Everitt I, Younge P, Barnett P. Paediatric sedation in emergency departments: What is our practice? Emerg Med 2002;14:62-6.

$26 \mathrm{Ng} \mathrm{KC}$, Ang SY. Sedation with ketamine for paediatric procedures in the emergency department-a review of 500 cases. Singapore Med J 2002;42:300-4

27 American College of Emergency Physicians. Clinical policy for procedural sedation and analgesia in the emergency department. Ann Emerg Med 1998:31:663-77

28 Australasian College of Emergency Medicine. Policy document-use of intravenous sedation for procedures in the emergency department. http:// www.acem.org.au/open/documents/sedation.htm (accessed Jan 2003)

29 Scottish Intercollegiate Guidelines Network. http://www.sign.ac.uk/ (accessed Jan 2003).

30 White PF, Way WL, Trevor AJ. Ketamine-its pharmacology and therapeutic uses. Anesthesiology 1982;56:119-36.

31 Reich DL, Silvay G. Ketamine: an update on the first twenty-five years of clinical experience. Can J Anaesth 1989;36:186-97.

32 Sadove MS, Shulman M, Hatano S, et al. Analgesic effects of ketamine in subdissociative doses. Anesth Analg 1971;50:452-7.

33 Komatsu T, Singh PK, Kimura T, et al. Differential effects of ketamine and midazolam on heart rate. Can J Anaesth 1995:42:1003-9.

34 Park GR, Manara AR, Medel L, et al. Ketamine infusion. Its use as a sedative, inotrope and bronchodilator in a critically ill patient. Anaesthesia 1987;42:980-3.

35 L'Hommedieu CS. The use of ketamine for the emergency department intubation of patients with status asthmaticus. Ann Emerg Med 1987; 16:568-71

36 Strube PJ, Hallam PL. Ketamine by continuous infusion in status asthmaticus. Anaesthesia 1986:41:1017-19.

37 Youssef-Ahmed MZ, Silver P, Nimkoff L, et al. Continuous infusion of ketamine in mechanically ventilated children with refractory bronchospasm. Intensive Care Medicine 1996;22:972-6.

38 Green SM, Nakamura R, Johnson NE. Ketamine sedation for pediatric procedures: Part 1, a prospective series. Ann Emerg Med 1990;19:1024-32.

39 Sussman DR. A comparative evaluation of ketamine anesthesia in children and adults. Anesthesiology 1974;40:459-64.

40 McGlone RG, Howes MC, Joshi M. The Lancaster experience of 2.0 to 2.5 $\mathrm{mg} / \mathrm{kg}$ intramuscular ketamine for paediatric sedation: 501 cases and analysis. Emerg Med J 2004;21:290-5. 
41 Smith JA Santer $\sqcup$. Respiratory arrest following intramuscular ketamine injection in a 4-year-old child. Ann Emerg Med 1993;22:613-15.

42 Greenhalgh T. How to read a paper: the Medline database. BMJ 1997;315:180-3

43 Younge PA, Kendall JM. Sedation for children requiring wound repair: a randomised controlled double blind comparison of oral midazolam and oral ketamine. Emerg Med J 2001;18:30-3.

44 Acworth JP, Purdie K, Clark RC. Intravenous ketamine plus midazolam is superior to intranasal midazolam for emergency paediatric procedural sedation. Emerg Med J 2001;18:39-45.

45 Green SM, Kuppermann N, Rothrock SG, et al. Predictors of adverse events with intramuscular ketamine sedation in children. Ann Emerg Med 2000;35:35-42.

46 Kapklein MJ, Slonim AD. Ketamine vs. Propofol: How safe is safe enough. Crit Care Med 2002;30:1384-6.

47 Green SM, Clem KJ, Rothrock SG. Ketamine safety profile in the developing world:survey of practioners. Acad Emerg Med 1996;3:598-604.

48 Ketchman DW. Where there is no anesthesiologist: the many uses of ketamine in the developing world. Trop Doct 1990;20:163-6.

49 Pederson L, Benumhof J. Incidence and magnitude of hypoxaemia with ketamine in a rural African hospital. Anaesthesia 1993;48:67-9.

50 Gofrit ON, Leibovici D, Shemer J, et al. Ketamine in the field: the use of ketamine for induction of anaesthesia before intubation in injured patients in the field. Injury 1997;28:41-3.

51 Tighe SQ, Rudland SV. Anesthesia in northern Iraq: an audit from a field hospital. Mil Med 1994;159:86-90.

52 Cottingham R, Thomson K. Use of ketamine in prolonged entrapment. J Accid Emerg Med 1994:11:189-91.

53 Trouwborst A, Weber Bk, Dufour D. Medical statistics of battlefield casualties. Injury 1987;18:96-9.

54 Green SM, Clark R, Hostetler MA, et al. Inadvertent ketamine overdose in children: clinical manifestations and outcome. Ann Emerg Med 1999:34:492-7.

55 Green SM, Klooster M, Harris T, et al. Ketamine sedation for pediatric gastroenterology procedures. J Pediatr Gastroenterol Nutr 2001;32:26-33.

56 Sherwin TS, Green SM, Khan A, et al. Does adjuctive midazolam reduce recovery agitation after ketamine sedation for pediatric procedures? A randomised, double-blind, placebo-controlled trial. Ann Emerg Med 2000;35:229-38

57 Wathen JE, Roback MG, MacKenzie T, et al. Does midazolam alter the clinical effects of intravenous ketamine sedation in children? A double-blind, randomised, controlled emergency department trial. Ann Emerg Med 2000;36:579-88.
58 Carley S, Martin B. Midazolam and emergence phenomena in children. Emerg Med J 2001;18:273-4

59 Paxton D. Treating postoperative nausea in children. Hospital Update 1996:428-30.3.

60 Green SM, Krauss B. Pulmonary aspiration risk during emergency department procedural sedation - an examination of the role of fasting and sedation depth. Acad Emerg Med 2002;9:35-42.

61 Green SM, Rothrock SG, Harris T, et al. Intravenous ketamine for pediatric sedation in the emergency department: safety profile with 156 cases. Acad Emerg Med 1998;5:971-6.

62 Peña BMG, Krauss B. Adverse events of percedural sedation and analgesia in a pediatric emergency department. Ann Emerg Med 1999;34:483-91.

63 Glickman A. Ketamine: the dissociative anesthetic and the development of a policy for its safe administration in the pediatric emergency department. J Emerg Nurs 1995;21:116-15.

64 Kennedy RM, Porter F, Miller JP, et al. Comparison of fentanyl/midazolam with ketamine/midazolam for pediatric orthopedic emergencies. Pediatrics 1998;102):956-63.

65 Murphy M. Sedation. Ann Emerg Med 1996;27:461-3.

66 Green SM, Hummel CB, Wittlake WA, et al. What is the optimal dose of intramuscular ketamine for pediatric sedation? Acad Emerg Med 1999;6:21-6.

67 Chudnofsky CR, Weber JE, Stoyanoff PJ, et al. A combination of midazolam and ketamine for procedural sedation and analgesia in adult emergency department patients. Acad Emerg Med 2000;7:278-81.

68 UK Academy of Medical Royal Colleges and their Faculties. Implementing and ensuring safe sedation practice for healthcare procedures in adults. Report of an Intercollegiate Working Party chaired by the Royal College of Anaesthetists. London: RCA, 2001.

69 Dental Teachers Sedation Group. Standards for conscious sedation in dentistry. Report of an Independent Expert Working Group. London: Dental Teachers Sedation Group, 2000. http://www.dstg.co.uk/oct2000sicsfd/ oct2000.htm (accessed Jan 2003)

70 Roscow C, Manberg PJ. Bispectral index monitoring. Anesthesiol Clin North Am 1998;2:89-107.

71 Royal College of Anaesthetists. Guidance on the provision of paediatric anaesthetic services. London: RCA, 2001. htpp: //www.rcoa.ac.uk/dload/ paediatric\%20services.pdf (accessed Jan 2003).

72 Green SM. Modern anesthesiologists receive limited training with ketamineimplications for emergency medicine.[Letter]. Acad Emerg Med 2000;7:839-41. 


\section{PostScript}

\section{LETTER}

\section{Monitoring junior doctors after a major incident}

The major incident that occurred in the capital on July 72005 put many junior doctors on the front line, seeing badly injured and traumatised patients. Exposure to such horrific sights will make many health care workers vulnerable to post traumatic stress disorder (PTSD).

Following the major incident, occupational health staff sent relevant line managers information alerting them to the symptoms of PTSD. In accordance with current recommendations, formal counselling was not routinely offered to staff immediately after the event. ${ }^{2}$ Evidence shows that it is not necessary for specific intervention until four to six weeks after the incident, when individuals have exhausted their normal coping mechanisms. It is difficult to achieve 'watchful waiting' in such a fluid environment as accident \& emergency. In particular, four weeks after this major incident, the majority of the junior doctors moved on to other posts.

Four weeks after the event, we carried out a departmental survey based upon Chris Brewin's Trauma Screening Questionnaire, in order to identify those more likely to be suffering from PTSD. ${ }^{3}$ The results showed that although no junior doctors were experiencing enough symptoms to suggest a greater risk of developing PTSD, only 50\% knew where to access counselling despite detailed information available on the hospital's intranet service.

We recommend that a senior staff member is responsible for informally following up junior doctors involved in a major incident. This should be four to six weeks after the event, potentially by postal questionnaire and should identify any on going problems. Posters advertising counselling should be clearly visible in communal staff areas and ultimately, every accident \& emergency department should have a follow up plan for remote monitoring of staff that were involved. This should be the final chapter of the major incident plan for any department.

J Blythe Department of Accident \& Emergency Medicine, Royal Free Hospital, London, UK

K Whitwell

Department of Accident \& Emergency Medicine, Royal Free Hospital, London, UK
Correspondence to: Dr Kerrie Whitwell, Accident \& Emergency Department, Royal Free Hospital, Pond Street, Hampstead, London NW3 2QG kerrie.whitwell@royalfree.nhs.uk

doi: 10.1136/emj.2005.030502

Accepted for publication 2 October 2005

\section{Reference}

1 Grieger TA, Fullerton CS, Ursano RJ, et al. Acute stress disorder, alcohol use and perception of safety among hospital staff after sniper attacks. Psychiatr Serv, 2003 Oct, 54(10): 1383-7.

2 Rose S, Bisson J, Churchill R, et al. Psychological debriefing for preventing post traumatic stress disorder (PTSD) (Review). The Cochrane Database of Systematic Reviews 2002, Issue 2. Art No. : CD000560, DOI:10.1002/14651858.

3 Brewin C, Rose S, Andrews B, et al. Brief screening instrument for post-traumatic stress disorder. British Journal of Psychiatry 2002;181:158-162.

\section{BOOK REVIEW}

\section{The high altitude medical handbook}

A J Pollard, D R Murdoch. Oxford: Third Edition, £23.50 (paperback). ISBN 1-85775849-8.

If imitation is the best form of flattery, then the authors of The High Altitude Medicine Handbook should consider themselves flattered indeed. The "mini micro" bootleg version of the first edition of the handbook, published in India, and widely available in bookshops in Kathmandu, has perhaps sold more copies to those departing on high altitude treks than the original. This illicit version was my first copy of the handbook and it lived in my back pocket when I was working as a medical officer on expedition in a remote corner of eastern Nepal. At high altitude, when cold, fatigue, and hypoxia muddled my brain, it was my constant reference text and bible.

I was therefore delighted to be asked to review the third edition, which was published in 2003 to coincide with the 50th anniversary of the first ascent to the summit of Mount Everest and the 25th anniversary of the first ascent without oxygen.

The handbook is not, nor does it set out to be, a definitive text on altitude medicine. There is therefore little on the physics of hypobaric hypoxia or the underlying pathophysiology of acute mountain sickness. Instead, it achieves exactly what it sets out to do: it is a clear, concise, commonsense guide to the management of all aspects of medical problems at high altitude. There are not only the expected chapters on high altitude illness, first aid and travel related illnesses, but also sections on children, ethics, culture, environmental and medicolegal concerns. All chapters are extensively referenced so readers can easily refer back to original literature. This third edition has been thoroughly revised to reflect the rapid increase in knowledge in the 5 years since the last edition.

The foreword by Sir Edmund Hilary reflects that both Andrew Pollard and David Murdoch are experienced mountaineers, Andrew Pollard having reached 8600 metres on the south col of Mount Everest in 1994. They are both experts in high altitude and expedition medicine and have a breadth of experience in managing medical conditions in some of the world's most challenging environments. David Murdoch worked for 2 years in the Everest Region, first at the Himalayan Rescue Organisation's first aid post at Pheriche, then at Kunde hospital. This makes the handbook occasionally controversial, always authoritative, and full of practical advice on how to overcome the technical challenges of practising medicine in such difficult conditions.

This is a valuable guide to have with you on expedition or any high altitude trek, but also includes valuable pre-departure planning information such as an appendix on what to include in a typical high altitude medicine kit list. Although the handbook is primarily aimed at medical practitioners, its straightforward text makes it accessible to lay travellers and can be highly recommended to anyone considering travelling to high altitude.

F Bellis

Competing interests: A Pollard (book author) and $\mathrm{F}$ Bellis (reviewer) are both members of Medex, a medical mountaineering and expedition club

\section{CORRECTION}

doi: 10.1136/emj.2005.5769corr

In the paper titled, Ketamine for paediatric sedation/analgesia in the emergency department (Emerg Med J 2004;21:275-80) reference 67 was incorrectly cited. The correct citation is; Chudnofsky CR, Weber JE, Stoyanoff PJ, et al. A combination of midazolam and ketemine for procedural sedation and analgesia in adult emergency department patients. Acad Emerg Med 2000; 7:228-35. 